\title{
RANCANG BANGUN ANTENA MIKROSTRIP PATCH CIRCULAR DENGAN TEKNIK LINIER ARRAY UNTUK FREKUENSI WIFI 2,4 GHZ
}

\author{
Surya Hadi Saputra ${ }^{1}$, Ari Endang Jayati ${ }^{2)}$, dan Erlinasari ${ }^{3)}$ \\ 1,2,3) Jurusan Teknik Elektro, Universitas Semarang \\ Jl. Soekarno Hatta, Semarang, Indonesia, 50196 \\ e-mail: surya.hs@gmail.com, ariendang@usm.ac.id, sari_erlina88@yahoo.com
}

\begin{abstract}
Microstrip antenna when the antenna is one of the very rapid development in telecommunications systems that applied to many modern telecommunication equipment today. One application is the wifi. Wifi (Wireless Fidelity) is a wellknown technology that utilizes an electronic device to exchange data wirelessly (using radio waves) over a computer network, including high-speed Internet connection, to provide a network connection to all users in the surrounding area. The purpose of this final project is to design microstrip patch antenna built a circular linier array that can be used for signal wifi stronger. The resulting microstrip antenna working in $2.4 \mathrm{GHz}$ band with the acquisition of gain $=3.4301 \mathrm{dBi}$, VSWR $=1.3749$ and radiation pattern unidirectional. This antenna design simulation using the software Ansoft High Frequency Structure Simulator v13. For linear circular microstrip patch antenna array then showed its parameters.
\end{abstract}

Keywords: Microstrip Antenna, Wifi, Array, VSWR, Gain

\begin{abstract}
ABSTRAK
Antena mikrostrip saat ini merupakan salah satu antena yang sangat pesat perkembangannya dalam sistem telekomunikasi sehingga banyak diaplikasikan pada peralatan-peralatan telekomunikasi modern saat ini. Salah satu aplikasinya adalah wifi. Wifi (Wireless Fidelity) adalah sebuah teknologi terkenal yang memanfaatkan peralatan elektronik untuk bertukar data secara nirkabel (menggunakan gelombang radio) melalui sebuah jaringan komputer, termasuk koneksi Internet berkecepatan tinggi, untuk memberi sebuah koneksi jaringan keseluruh pengguna dalam area di sekitarnya.Tujuan dari Tugas Akhir ini adalah merancang bangun sebuah antenna mikrostrip patch circular linier array yang dapat digunakan untuk memperkuat sinyal wifi. Antena mikrostrip yang dihasilkan bekerja pada frekuensi 2,4 GHz dengan perolehan gain = 3,4301 dBi, VSWR =1,3749 dan pola radiasi unidirectional. Simulasi perencangan antena ini menggunakan software Ansoft High Frequency Structure Simulator v13. Untuk antena mikrostrip patch circular linier array maka didapatkan hasil parameter-parameternya.
\end{abstract}

Kata Kunci: Antena Mikrostrip, Wifi, Array, VSWR, Gain.

\section{Pendahuluan}

$\mathrm{A}$ ntena mikrostrip adalah suatu antena konduktor metal yang menempel di atas groundplane yang diantaranya terdapat bahan dielektrik. Antena mikrostrip terdiri atas 3 komponen yaitu: groundplane, substrat, dan patch peradiasi. Antena mikrostrip merupakan salah satu antena gelombang mikro yang digunakan sebagai radiator pada sejumlah sistem telekomunikasi modern saat ini. Ada beberapa macam konfigurasi antena array, diantaranya linear, planar, dan circular. Masing-masing konfigurasi memiliki keuntungan, misalnya linear array memiliki kelebihan dalam perhitungan yang tidak terlalu rumit, sedangkan planar array memiliki kelebihan dalam pengaturan dan pengendalian arah pola radiasi.

Penelitian tentang perancangan antenna pada haringan wifi telah banyak dilakukan [1]. Demikian juga penelitian tentang antenna mikrostrip sangat banyak dijumpai di literatur. Mahendra dkk meneliti tentang antenna bow tie pada aplikasi ultra wideband [2]. Penggunaan antenna mikrostrip pada jaringan wifi telah banyak dibahas. Perancangan tentang antena mikrostrip dua elemen patch berbentuk segitiga juga telah dilakukan [3]. Pembuatan antenna mikrostrip berbentuk lingkaran pada wifi juga telah diselidiki [4]. Perancangan antenna mikrostrip yang berbentuk segi empat juga telah dilakukan [5]. Penelitian tentang perancangan antenna mikrostrip array berbentuk circular telah dilakukan oleh [6]. Akan tetapi penerapan antenna mikrostrip array pada wifi masih sangat sedikit.

Pada penelitian ini, akan dibahas tentang perancangan antena Mikrostrip patch circular dengan teknik linier array untuk memperkuat sinyal wifi pada frekuensi 2,4 GHz. Parameter-parameter utama yang akan dianalisis adalah VSWR (Voltage Standing Wave Ratio) dan gain.

Organisasi dari paper ini adalah: Seksi II menjelaskan tentang model system antenna, Seksi III membahas perancangan antena mikrostrip cicular linier array. Pada seksi IV membahas tentang hasil pengujian perancangan antenna yang dibuat, selanjutnya Seksi V adalah kesimpulan. 


\section{MOdel SISTEM}

Mikrostrip terdiri dari dua kata, yaitu mikro (sangat tipis/kecil) dan strip (bilah/potongan). Antena mikrostrip dapat didefinisikan sebagai salah satu jenis antena yang mempunyai bentuk seperti bilah/potongan yang mempunyai ukuran sangat tipis/kecil. Antena mikrostrip bisa memiliki berbagai macam bentuk seperti lingkaran, segitiga, kotak atau persegi panjang.

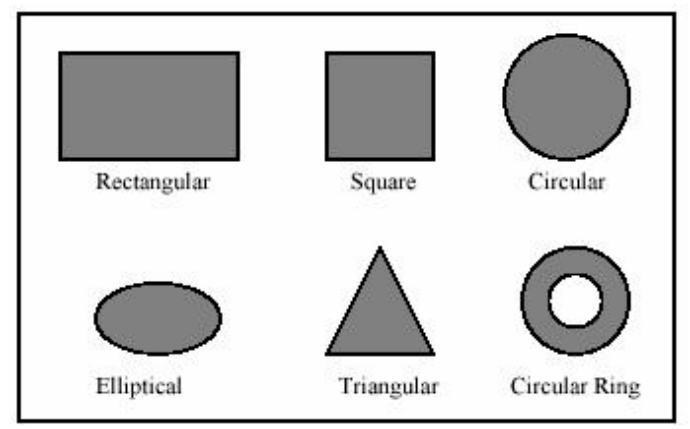

Gambar. 1. Bentuk Antena Mikrostrip

Antena mikrostrip yang berbentuk array memiliki beberapa kelebihan dibanding dengan antena mikrostrip konvensional. Kelebihannya yaitu memiliki bandwidth dan gain yang lebih besar. Disamping memiliki kelebihan, antena jenis ini juga memiliki kelemahan, yaitu membutuhkan suatu jalur transmisi/pencatu antara elemen peradiasi dan input connector untuk mengurangi rugi-rugi sehingga mengurangi efisiensi antena. Pada antena array terdapat Array Factor (AF) yang merupakan pengali dari medan elektrik dari elemen tunggal. Array Factor inilah yang menentukan bagaimana pola radiasi dan seberapa besar tingkat daya yang diradiasikan oleh antena tersebut.

Antena mikrostrip dengan patch circular memilki performa yang sama dengan antena mikrostrip patch segiempat. Pada aplikasi tertentu, seperti array, patch circular ini akan menghasilkan keuntungan dibandingkan dengan patch yang lainnya. Antena mikrostrip dengan patch circular ini akan lebih mudah dimodifikasi untuk menghasilkan jarak nilai impedansi, pola radiasi, dan frekuensi kerja. Untuk menganalisis antena mikrostrip patch circular ini banyak metode yang telah digunakan, termasuk diantaranya dengan menggunakan model rongga (cavity model).

Rumus untuk mencari nilai jari-jari patch digunakan persamaan dibawah ini:

$$
a=\frac{8.794 \times 10^{\circ}}{f r \times 10^{\circ} \sqrt{\varepsilon_{r}}}
$$

Dimana :

$a$ = panjang jari-jari $(\mathrm{mm})$

$\mathrm{fr}=$ frekuensi kerja antena $(\mathrm{Hz})$

$\mathcal{E} r=$ Konstanta dielektrik substrat $(4,4)$
Definisi VSWR adalah rasio amplitudo tegangan maksimum terhadap amplitudo tegangan minimum dalam pola tegangan berdiri. Fluktuasi level daya yang terjadi dikarenakan adanya ketidaksesuaian saluran transmisi dengan beban. Besarnya nilai VSWR bervariasi antara 1 sampai (tak terhingga). Semakin tinggi VSWR, semakin besar pula ketidaksesuaian.

Untuk menentukan dimensi elemen peradiasi, maka terlebih dahulu harus ditentukan frekuensi kerja (f) yang digunakan untuk mencari panjang gelombang diruang bebas $(\lambda 0)$ :

$$
\lambda o=\frac{c}{f}
$$

Setelah nilai panjang gelombang di ruang bebas $(\lambda 0)$ diperoleh, maka panjang gelombang pada saluran transmisi $(l)$ dengan Persamaan berikut ini:

$$
l=\frac{\lambda 0}{\sqrt{\varepsilon r}}
$$

Impedansi karakteristik antena mikrostrip ditentukan dengan Persamaan berikut:

$$
Z L=60 \frac{l}{W}
$$

Dimana :

W : Diameter elemen peradiasi (mm).

Salah satu pengukuran yang penting untuk menggambarkan performa suatu antena adalah gain (penguatan). Meski gain antena erat kaitannya dengan directivity, gain adalah pengukuran yang memperhitungkan efisiensi antena maupun keterarahannya.

$$
\begin{array}{r}
\mathrm{G}(\mathrm{dB})=10 \log G \\
G=\eta \times \text { Dtotal }
\end{array}
$$

Dengan :

$\eta=$ efisiensi antena

$G=$ gain antena uji $(d B)$

\section{Perancangan}

Dalam pemilihan jenis substrate sangat dibutuhkan pengetahuan tentang spesfikasi umum dari substrate, kualitasnya, ketersediannya, dan yang tidak kalah penting adalah harga atau biaya yang harus dikeluarkan untuk mendapatkannya, karena akan mempengaruhi nilai jual ketika akan di buat secara massal untuk dipasarkan.

TABEL I

SPESIFIKASI SUBSTRAT

\begin{tabular}{cc}
\hline Jenis Substrat & FR4 epoxy \\
\hline Konstanta Dielektrik Relatif $(\boldsymbol{\varepsilon r})$ & 4,4 \\
\hline Dieletric Loss Tangent $(\tan \delta)$ & 0,02 \\
\hline Ketebalan Substrat $(\mathrm{h})$ & $0,16 \mathrm{~cm}$ \\
\hline
\end{tabular}


Antena yang akan dirancang pada penelitian ini adalah antena mikrostrip dengan frekuensi kerja 2,4 GHz. Untuk perancangan awal dari dimensi antena digunakan perhitungan pada antena mikrostrip dengan patch berbentuk lingkaran dengan menggunakan persamaan 2.35 sebagai berikut:

$$
\begin{array}{r}
a=\frac{8.794 \times 10^{9}}{f r x 10^{9} \sqrt{\varepsilon r}} \\
a=\frac{8.794 \times 10^{9}}{2.4 \times 10^{9} \sqrt{4,4}} \\
a=17.4 \mathrm{~mm}
\end{array}
$$

Saluran pencatu yang digunakan pada perancangan ini diharapkan mempunyai atau paling tidak mendekati masukan sebesar $50 \Omega$. Untuk mendapatkan nilai impedansi tersebut dilakukan pengaturan lebar dari saluran pencatu dilakukan pengaturan lebar dari saluran dengan menggunakan program Txline 2003 didapatkan panjang saluran pencatu $30 \mathrm{~mm}$ dan lebar saluran pencatu sebesar $3 \mathrm{~mm}$.

Adapun jarak antar elemen pada antena yang dirancang pada penelitian ini sekitar seperempat panjang gelombang $(d=\lambda / 4)$. Jarak antar elemen ini dapat diatur untuk mendapatkan hasil yang lebih optimal yaitu untuk meningkatkan magnitude hasil simulasi pola radiasi agar lebih besar dari yang dihasilkan pada rancangan elemen tunggal. Adapun jarak antar elemen didapat dari penggunaan persamaan berikut:

$$
\begin{aligned}
& d=\frac{c}{4 f} \\
& d=\frac{3 \times 10^{8}}{4 \times 2,4 \times 10^{9}} \\
& d=31,25 \mathrm{~mm}
\end{aligned}
$$

Dari Persamaan diatas didapatlah jarak awal antar elemen adalah 31,25 mm, setelah diketahui jarak antar elemen hal ini akan memudahkan untuk meletakan posisi elemen yang akan dirancang, bisa nanti diperlukan penyesuaian jarak tiap elemen pada antena tersebut.

\section{HASIL PENGUJIAN}

Hasil Simulasi Antena Mikrostrip Patch Circular Linier Array seperti Gambar 2.

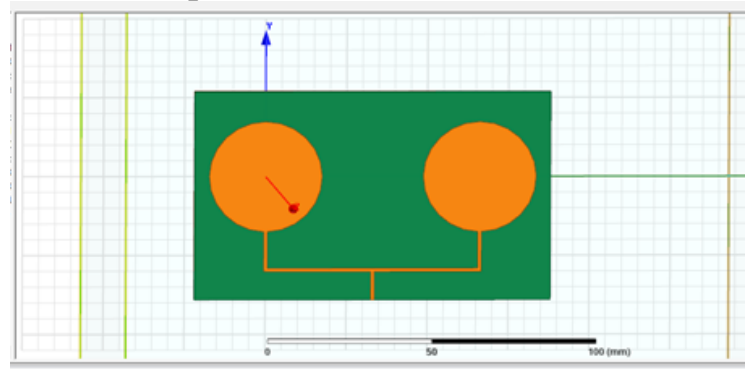

Gambar. 2. Desain Antena Mikrostrip
TABEL 2

HASIL SIMULASI ANTENA

\begin{tabular}{lll}
\hline Parameter & Elemen tunggal & 2 Elemen \\
\hline VSWR & 1,2638 & 1,3749 \\
\hline Gain $(\mathrm{dBi})$ & 1,9519 & 3,4301 \\
\hline
\end{tabular}

Setelah melakukan penyesuaian jarak antar elemen dilakukan maka dapat dibandingkan parameter antena mikrostrip patch circular elemen tunggal dengan antena mikrostrip patch circular 2 elemen dengan teknik linier array seperti pada Tabel 2 .

Pengujian Antena Mikrostrip Patch Circular Linier Array menggunakan aplikasi WirelessMon, dilihat datadata access point yang didapatkan dari percobaan di dalam rumah pada tanggal 10 januari 2017, menggunakan access point hotspot handphone.

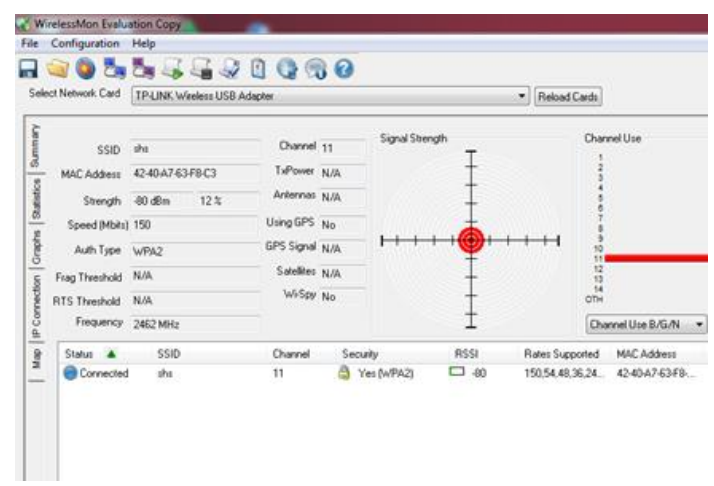

Gambar. 3. Tanpa Menggunakan Antena Mikrostrip

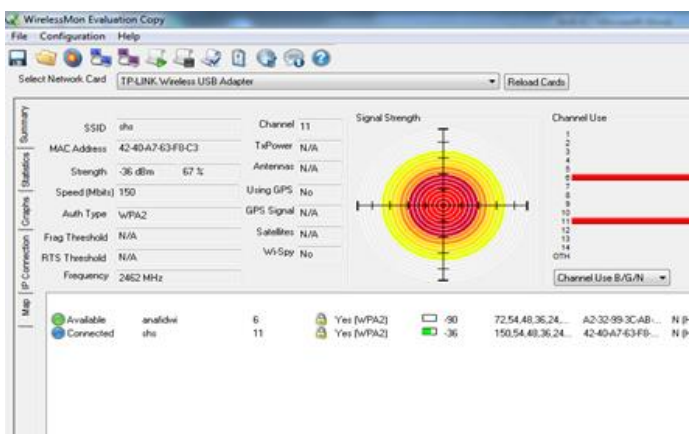

Gambar. 4. Menggunakan Antena Mikrostrip

Dari Gambar 3 dan 4 diatas, didapatkan bahwa ketika USB wireless adapter dihubungkan dengan antena mikrostrip patch circular linier array, access point yang didapat lebih banyak dibandingkan tanpa menggunakan antena, ini menandakan bahwa rancangan antena mikrostrip patch circular linier array telah bekerja sesuai dengan diinginkan. Selanjutnya akan dijelaskan pergerakan sinyal yang diterima menggunakan antena mikrostrip patch circular linier array dan tanpa menggunakan antena. Adapun access 
point yang akan diambil datanya ialah access point yang berasal dari SHS. Dengan aplikasi WirelessMon dapat dilihat kuat sinyal yang diterima baik menggunakan antena mikrostrip maupun tanpa antena.

Dari hasil data yang diperoleh dengan menggunakan software WirelessMon dapat dilihat bahwa perbandingan antara antena mikrostrip patch circular linier array dengan tidak menggunakan antena. Semakin banyak sinyal yang dapat ditangkap dan semakin jauh jarak jangkauan access point yang dapat dideteksi oleh antena mikrostrip patch circular linier array.

Dari gambar 5 dan 6 diatas didapat besar kekuatan sinyal tanpa antena sebesar $-77 \mathrm{dBm}$ sedangkan saat menggunakan antena mikrostrip patch circular linier array sebesar $-70 \mathrm{dBm}$. Setelah mendapat nilai level penerimaan sinyal dari kedua antena diatas maka gain antena dapat dihitung menggunakan Persamaan sebagai berikut :

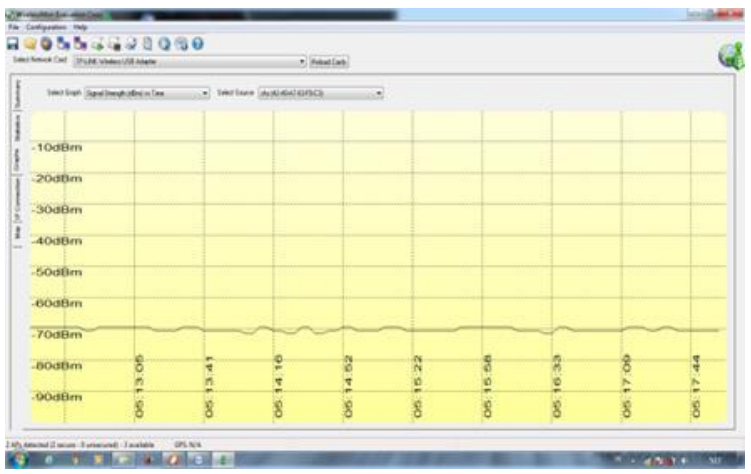

Gambar. 5. Pengujian Gain Tanpa Menggunakan Antena Mikrostrip

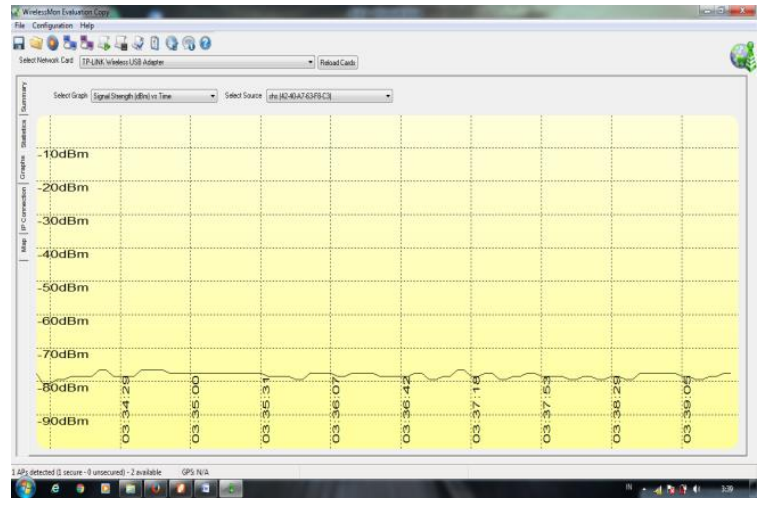

Gambar. 6. Pengujian Gain Dengan Menggunakan Antena Mikrostrip

$$
\begin{aligned}
& \mathrm{Ga}(d B)=\mathrm{Pa}(\mathrm{dBm})-\mathrm{Ps}(d B m)+\mathrm{Gs}(\mathrm{dBi}) \\
& \mathrm{Ga}(d B)=-70-(-77)+0 \\
& \mathrm{Ga}(\mathrm{dB})=7 \mathrm{dBi}
\end{aligned}
$$

Dari Persamaan diatas didapat besar gain dari antena mikrostrip patch circular linier array yaitu sebesar 10 dBi. Nilai ini lebih baik dibanding kan dengan nilai hasil simulasi yaitu sebesar $3,4 \mathrm{dBi}$, hal ini bisa saja disebabkan faktor lingkungan, proses pembuatan antena mikrostrip ini, namun dari nilai menunjukan bahwa antena yang dibuat telah bekerja sesuai dengan yang diinginkan.

Sebelum mencari besar VSWR harus mengetahui nilai panjang gelombang di ruang bebas terlebih dahulu, untuk mencari nilai panjang gelombang diruang bebas menggunakan rumus berikut :

$$
\begin{gathered}
\lambda o=\frac{c}{f} \\
\lambda o=\frac{3 \times 10^{8}}{2.4 \times 10^{9}} \\
=125 \mathrm{~mm}
\end{gathered}
$$

Setelah nilai panjang gelombang di ruang bebas $(\lambda 0)$ diperoleh, maka menghitung panjang gelombang pada saluran transmisi $(l)$ dan menghitung impedansi beban (ZL) berikut ini:

$$
\begin{gathered}
l=\frac{\lambda 0}{\sqrt{\varepsilon r}} \\
l=\frac{125}{\sqrt{4.4}} \\
=59.59 \mathrm{~mm} \\
Z I=60 \frac{l}{\pi} \\
Z I=60 \frac{59.59}{34.8} \\
=102.70 \mathrm{hm}
\end{gathered}
$$

Dari nilai impedansi beban diatas maka dicari besar koefisien refleksi dan hasilnya sebagai berikut ini:

$$
\begin{aligned}
& \Gamma=\frac{Z L-Z 0}{Z L+Z 0} \\
& =\frac{102.741-50}{102.741+50} \\
& =0.345
\end{aligned}
$$

Selanjutnya dari nilai koefisien refleksi diatas maka dicari VSWR secara teori. Untuk menghitung nilai VSWR dapat dicari. Adapun hasilnya sebagai berikut:

$$
\begin{aligned}
& V S W R=\frac{1-|\Gamma|}{1+|\Gamma|} \\
& =\frac{1-|0.345|}{1+|0.345|} \\
& =2.053
\end{aligned}
$$

Dari nilai diatas diketahui nilai VSWR secara teori didapat adalah 2,053. Menurut hasil simulasi, pada proses penyesuaian lebar saluran pencatu mendapatkan nilai VSWR elemen tunggal sebesar 3,3 sampai 1,2, hal 
ini menandakan bahwa secara teori nilai VSWR yang didapat cukup jauh berbeda dengan hasil simulasi hal ini dipengaruhi lebar saluran pencatu, panjang saluran pencatu dan jari-jari patch sehingga dalam pembuatan antena mikrostrip ini diperlukan penyesuaian lebar saluran pencatu dan panjang saluran pencatu agar mendapatkan nilai VSWR yang tidak jauh berbeda dengan hasil teori.

Adapun besar gain yang didapat dari antena mikrostrip patch circular linier array secara perhitungan dapat dicari menggunakan persamaan 2.25 namun terlebih dahulu harus dicari pengarahan (directivity) dari antena ini. Untuk mencari directivity dari antena mikrostrip patch circular linier array dapat digunakan persamaan berikut:

$$
\begin{aligned}
& I_{1}=\sqrt{\frac{120 W^{2} \pi^{2}}{90 \lambda 0^{2}}} \\
& =\sqrt{\frac{120(34.8)^{2}(3.14)^{2}}{90(125)^{2}}} \\
& =1.01
\end{aligned}
$$

Dari nilai $I 1$ maka didapat dihitung besarnya nilai directivity single slot dari antena mikrostrip ini. Adapun besar nilai directivity dapat dihitung dengan menggunakan persamaan berikut ini:

$$
\begin{aligned}
& D=\frac{4 W^{2} \pi^{2}}{\lambda_{0}^{2} I_{1}} \\
= & \frac{4(34.8)^{2}(3.14)^{2}}{(125)^{2} 1.01} \\
= & 3.026
\end{aligned}
$$

Setelah nilai directivity didapat maka dapat dicari nilai directivity susun dengan menggunakan Persamaan 2.13 berikut ini:

$$
\begin{aligned}
& \text { Dsusun }=2 D \\
& =2 \times 3.026 \\
& =6.052
\end{aligned}
$$

Selanjutnya dengan didapatnya nilai directivity total didapatlah besar gain secara teori. Untuk mencari besar gain dapat dihitung menggunakan Persamaan 2.25 dan 2.27 berikut ini:

$$
\begin{aligned}
& G=\eta \times \text { Dtotal } \\
& =60 \% \times 6.052 \\
& =3.63 \\
& \begin{aligned}
\mathrm{G}(\mathrm{dB}) & =10 \log G \\
& =10 \log 3.63 \\
& =5.59 \mathrm{~dB}
\end{aligned}
\end{aligned}
$$

TABEL 3

PERBANDINGAN Hasil TeORI, SIMULASI DAN PENGUJIAN

\begin{tabular}{lllll}
\hline Parameter & $\begin{array}{l}\text { Perhitungan } \\
\text { Teori }\end{array}$ & $\begin{array}{l}\text { Hasil Sim- } \\
\text { ulasi }\end{array}$ & $\begin{array}{l}\text { Hasil } \\
\text { gujian }\end{array}$ & Pen- \\
\hline VSWR & 2,053 & 1,3749 & - \\
\hline Gain $(\mathrm{dBi})$ & 5,59 & 3,4301 & 7 \\
\hline
\end{tabular}

Nilai gain yang didapatkan teori sebesar 5,59 dBi sedangkan dihasilkan simulasi setelah dilakukan penyesuaian lebar saluran pencatu antena mikrostrip adalah 3,4301 dBi dan pada pengujian antena besar gain $7 \mathrm{dBi}$. Perbedaan nilai gain sebesar itu dikarenakan pada simulasi melalui penyesuaian penyesuaian dimensi patch dan saluran pencatu. Besar nilai gain yang diuji melebihi nilai gain yang disimulasikan maka rancangan antena mikrostrip patch circular linier array ini dapat dikatakan optimal karena nilai gain yang dihasilkan tersebut telah berjalan dengan baik.

\section{KESIMPULAN}

Pada penelitian ini telah berhasil dirancang antena mikrostrip patch circular linier array sebagai penguat sinyal wifi. PCB fiberglass epoxy dapat digunakan sebagai substrate pembuatan antena microstrip. Besarnya Jari-jari patch antena sangat mempengaruhi frekuensi kerja pada antena microstrip patch circular linier array, semakin besar nilai frekuensi maka semakin kecil jarijari patch antena. Jumlah patch antena array sangat mempengaruhi nilai gain yang dihasilkan. Semakin banyak jumlah patch antena akan semakin besar gain yang dihasilkan. Besarnya nilai panjang pencatu dan lebar pencatu sangat mempengaruhi nilai VSWR, sehingga di perlukan penyesuaian lebar dan panjang saluran pencatu. Spesifikasi antena mikrostrip patch circular linier array dua elemen terbuat dari bahan PCB fiberglass epoxy yang memiliki konstanta dielektrik 4.4, memiliki VSWR sebesar 1,3749 dan menghasilkan gain sebesar 7dBi. Perbedaan nilai gain disebabkan berbagai hal antara lain kondisi lingkungan tempat pengujian, human error, serta ketelitian dalam pembuatan. Penelitian selanjutnya akan divariasi bahan untuk substrate dan jumlah array lebih banyak.

\section{Daftar Pustaka}

[1] Windi Kurnia, 2010, Rancang Bangun Antena 2,4 MHz Untuk Jaringan Wireless-LAN, Skrpsi, Universitas Indonesia, Jakarta.

[2] Adhi Mahendra, 2012, Perancangan Antena Microstrip Bow-Tie pada Aplikasi Ultra Wideband, Jurnal Ilmiah Elite Elektro, VOL.3, NO.2, September 2012: 79-88, Jakarta. 
[3] Darsono M, 2012, Rancang Bangun Antena Microstrip Dua Elemen Patch Segitiga Untuk Aplikasi Wireless Fidelity, Jurnal EECCIS VOL. 6, NO. 2, Desmber, Jakarta.

[4] Iqbal, M, 2012, Rancang Bangun Antena Mikrostrip Patch Lingkaran Untuk Memperkuat Sinyal Wi-fi, Skripsi, Universitas Harapan, Medan.

[5] Muhammad Rudy Hermansyah, 2010, Rancang Bangun Antena Microstrip Patch Segi Empat Untuk Aplikasi Wireless-LAN, Skripsi, Universitas Sumatera Utara, Medan.

[6] Neronzie Julardi, 2013, Rancang Bangun Antena Mikrostrip Patch Circular (2.45GHZ) Dengan Teknik Planar Array Sebagai Penguat Sinyal Wi-fi, Skripsi, Universitas Sumatera Utara, Medan 